\title{
Ozone Initiates Human-Derived Emission of Nanocluster Aerosols
}

Yang, Shen; Licina, Dusan; Weschler, Charles J; Wang, Nijing; Zannoni, Nora; Li, Mengze; Vanhanen, Joonas; Langer, Sarka; Wargocki, Pawel; Williams, Jonathan

Total number of authors:

11

Published in:

Environmental Science and Technology

Link to article, DOI:

10.1021/acs.est.1c03379

Publication date:

2021

Document Version

Early version, also known as pre-print

Link back to DTU Orbit

Citation (APA):

Yang, S., Licina, D., Weschler, C. J., Wang, N., Zannoni, N., Li, M., Vanhanen, J., Langer, S., Wargocki, P., Williams, J., \& Bekö, G. (2021). Ozone Initiates Human-Derived Emission of Nanocluster Aerosols.

Environmental Science and Technology, 55(21), 14536-14545. https://doi.org/10.1021/acs.est.1c03379

\section{General rights}

Copyright and moral rights for the publications made accessible in the public portal are retained by the authors and/or other copyright owners and it is a condition of accessing publications that users recognise and abide by the legal requirements associated with these rights.

- Users may download and print one copy of any publication from the public portal for the purpose of private study or research.

- You may not further distribute the material or use it for any profit-making activity or commercial gain

- You may freely distribute the URL identifying the publication in the public portal 


\section{Environmental Science \& Technology Manuscript}

\section{Ozone Initiates Human-derived Emission of Nanocluster Aerosols}

2 Shen Yang, ${ }^{1}$ Dusan Licina, ${ }^{1 *}$ Charles J. Weschler,${ }^{2,3}$ Nijing Wang, ${ }^{4}$ Nora Zannoni, ${ }^{4}$ Mengze Li, ${ }^{4}$ 3 Joonas Vanhanen, ${ }^{5}$ Sarka Langer, ${ }^{6,7}$ Pawel Wargocki, ${ }^{2}$ Jonathan Williams, ${ }^{4,8}$ Gabriel Bekö ${ }^{2 *}$ $4 \quad$ Affiliations

$5 \quad{ }^{1}$ Human-Oriented Built Environment Lab, School of Architecture, Civil and Environmental 6 Engineering, École Polytechnique Fédérale de Lausanne (EPFL), 1015 Lausanne, $7 \quad$ Switzerland

Corresponding authors:

Dusan Licina (usan.licina@epfl.ch); Gabriel Bekö (gab@byg.dtu.dk) 


\section{Abstract}

Nanocluster aerosols (NCA, particles $<3 \mathrm{~nm}$ ) are important players in driving climate feedbacks and processes that impact human health. This study reports, for the first time, NCA formation when gas-phase ozone reacts with human surfaces. In an occupied climatecontrolled chamber, we detected NCA only when ozone was present. NCA emissions were dependent on clothing coverage, occupant age, air temperature and humidity. Ozoneinitiated chemistry with human skin lipids (particularly their primary surface reaction products) is the key mechanism driving NCA emissions, as evidenced by positive correlations with squalene in human skin wipe samples and known gaseous products from ozonolysis of skin lipids. Oxidation by $\mathrm{OH}$ radicals, autoxidation reactions, and humanemitted $\mathrm{NH}_{3}$ may also play a role in NCA formation. Such chemical processes are anticipated to generate aerosols of the smallest size $(1.18-1.55 \mathrm{~nm})$, whereas larger clusters result from subsequent growth of the smaller aerosols. This study shows that whenever we encounter ozone indoors, where we spend most of our lives, nanocluster aerosols will be produced in the air around us.

\section{Synopsis}

Chamber studies reveal nanocluster aerosol emissions from ozone-human chemistry occurring in indoor air and the potential formation mechanisms.

\section{Keywords}

Ozone chemistry; Indoor air; Human skin lipids; Particle formation; Molecular clusters 


\section{$45 \quad$ TOC graphic}

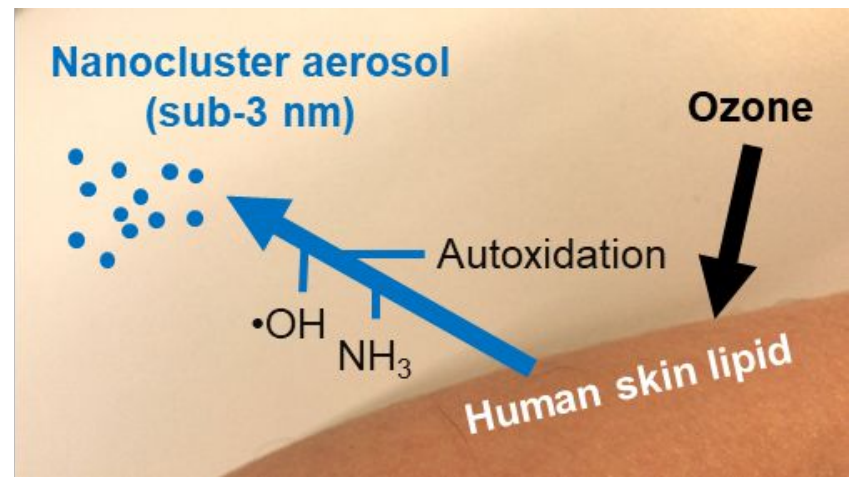




\section{Introduction}

Airborne nanoparticles of sub-3 nm size are termed nanocluster aerosol (NCA) particles. By number, NCA particles constitute a considerable fraction of urban aerosols as they originate directly from traffic emissions ${ }^{1}$ and via atmospheric processes, ${ }^{2}$ with number concentrations ranging from $10^{2}$ to $10^{5} \mathrm{~cm}^{-3} .3$ Previous studies have shown that NCA are precursors of new nanoparticle formation, ${ }^{4}$ which is a key phenomenon associated with the growth of atmospheric aerosol particles into cloud condensation nuclei and hence climate feedbacks. ${ }^{5}$

Owing to recent advancements in fast-response and high-time-resolution NCA measurement technologies, ${ }^{6}$ recent indoor studies have started to reveal the importance of NCA characterization in this relatively understudied environment. Results from a field campaign in a test house with periodic occupancy showed that NCA could dominate total particle number, particularly during cooking and dining $\left(10^{5}-10^{6} \mathrm{~cm}^{-3}\right) .{ }^{7}$ It has been shown previously that considerable numbers of NCA can be generated from cooking, ${ }^{8}$ burning candles, ${ }^{9}$ 3D printing, ${ }^{10}$ and thermal desorption of semi-volatile organic compounds (SVOCs). ${ }^{11}$ Although the specific health impacts of NCA remain unknown, exposure to elevated concentrations of nanoparticles $(<100 \mathrm{~nm})$ has been linked to adverse health outcomes, due to their deep penetration into the human lung and even neuronal transport to the brain. ${ }^{12}$

The impact of ozone on NCA formation from reactive gas phase pollutants is well documented outdoors. ${ }^{13}$ It can be hypothesized that ozone initiated NCA generation indoors occurs to an even greater extent, owing to the large surface-to-volume ratios promoting surface-chemistry, ${ }^{14}$ and the presence of diverse and abundant volatile organic compounds (VOCs) $)^{15}$ and other precursors available for ozone chemistry. ${ }^{16}$ 
Humans and their clothing play an important role in indoor ozone chemistry. Skin lipids contain squalene and unsaturated fatty acids, which rapidly react with ambient ozone. ${ }^{17}$ These reactions are a potent source of indoor carbonyls, dicarbonyls and hydroxycarbonyls. ${ }^{18-21}$ Reaction of ozone with human skin or previously worn clothing also generates ultrafine particles in the $10-100 \mathrm{~nm}$ diameter range..$^{22,23}$ These ultrafine particles presumably originate from the growth of NCA, as has been observed in outdoor air, ${ }^{24,25}$ although this has not yet been demonstrated.

This study reports NCA formation from ozone-human chemistry and the associated driving parameters. Within the framework of the ICHEAR (Indoor Chemical Human Emissions and Reactivity) project, ${ }^{26}$ we measured the emission of $1.18-4 \mathrm{~nm}$ aerosol particles from human volunteers in the absence and presence of ozone within a climate-controlled chamber. We investigated the effects of the extent of clothing (covered body surface area), air temperature and humidity, and the age of the human subjects. Together with highly sensitive VOC and $\mathrm{OH}$ reactivity measurements, we probed the underlying mechanisms and principal drivers responsible for the observed NCA formation.

\section{Methods}

\section{Climate chamber}

A detailed description and experimental methodology are given in Bekö et al. ${ }^{26}$ Briefly, measurements were made in a $22.5 \mathrm{~m}^{3}$ stainless-steel climate-controlled chamber (Fig. S1). ${ }^{26,27}$ The chamber was ventilated with $100 \%$ outdoor air at an air change rate of $3.2 \pm$ $0.1 \mathrm{~h}^{-1}$. A combination of newly installed F7 fiber filters and high efficiency activated carbon molecular filters ensured an NCA- and ozone-free background in the unoccupied chamber $\left(<1 \mathrm{NCA} / \mathrm{cm}^{3}\right.$ and $<1 \mathrm{ppb}$, respectively). The air was supplied through the perforated floor and exhausted via an outlet in the ceiling, where NCA concentrations were 
measured. During conditions with ozone present, ozone was generated in the supply air duct by a Jelight 600 UV generator (Jelight Co. Inc., USA). The chamber was furnished with a table and four wire mesh metal chairs. Additionally, two pedestal fans facing the chamber walls ensured air mixing. To minimize reactive surfaces other than human volunteers, the chamber and furniture surfaces were thoroughly cleaned prior to the experimental campaign and at regular intervals during the campaign.

\section{Experimental Procedure}

Five groups of four human volunteers were recruited: three young-adult groups (A1-A3; average age 25.1 years, range 19-30), one teenager group (T4; average age 13.8 years, range 13-15), and one senior group (S5; average age 70.5 years, range 68-72). NCA emissions were investigated for groups A1, A2, T4 and S5. Groups A2, T4 and S5 consisted of two males and two females, while group A1 included three males and one female.

The volunteers were asked to take a shower in the evening prior to experiments using provided perfume- and odorant-free liquid soap and shampoo. They were asked not to apply any personal care products. Prior to entering the chamber the following morning, the volunteers were asked to change into a set of clothes provided by the researchers. The clothing was washed with perfume- and odorant-free laundry detergent once directly after purchase, tumble dried and sealed in individual zip-lock bags. In the chamber, the volunteers sat around the table and were allowed to use their smartphones or provided computer tablets. They were not allowed to bring anything else other than their smartphones to the chamber. The volunteers were asked to stand up and stretch/walk within the chamber for several minutes every hour.

The chamber conditions were set the night before each experiment to ensure that they had reached steady state at the beginning of the experiment. The chamber door was closed 
during the entire experiment. After the volunteers exited the chamber, the door was kept closed for 30 minutes and the decay of the NCA concentrations was measured.

Fifteen experiments were performed to investigate NCA emissions from ozone-human chemistry. To demonstrate the influence of ozone on NCA emissions, two types of

\section{Instrumentation and Quality Control}


NCA in the chamber were sampled at $2.5 \mathrm{~L} / \mathrm{min}$ flow rate and measured in real time with a Nano Condensation Nucleus Counter (Airmodus A11 nCNC System, Airmodus, Finland), consisting of a Particle Size Magnifier (PSM A10) and a Condensation Particle Counter (CPC A20). ${ }^{28}$ The PSM is used to grow small particles to the detectable size range of the $\mathrm{CPC}$ with the mixing type principle. ${ }^{29}$ The mixing ratio can be changed rapidly, resulting in concomitant size variations in the smallest particles that can be magnified by the PSM. By scanning the mixing ratio continuously, the size distribution of aerosols in the 1-4 nm range can be measured. Relative to other particle detection technologies, such as the Scanning Mobility Particle Sizer (SMPS), this approach minimizes the losses of the smallest aerosols because there is no prior size selection or particle charging. The instrument has been widely applied in atmospheric outdoor NCA measurements and in a limited number of indoor measurements. ${ }^{3,7}$ Prior to the campaign, the instrument was fully serviced and calibrated using monodisperse NiCr-oxide particles for the $1-4 \mathrm{~nm}$ size range. ${ }^{26}$ The PSM ran in the scanning mode with the saturator flow scanning at a constant speed, resulting in the detection of 1.18-4 $\mathrm{nm}$ aerosols. A complete scan included two 2-min periods: the saturator flow climbing from 0.1 to $1.3 \mathrm{~L} / \mathrm{min}$ (up-scan), and then decreasing back to $0.1 \mathrm{~L} / \mathrm{min}$ (down-scan). Typically, we averaged aerosol particle concentrations of each size bin measured in the two periods and thus have a time resolution of $4 \mathrm{~min}$. When the variation in NCA concentrations was large, we adopted the 2-min resolution to better capture the NCA dynamics.

The ozone concentration inside the chamber was measured with a time resolution of $10 \mathrm{~s}$ with an ozone monitor (Model 205, 2B Technologies, USA) at $2.0 \mathrm{~L} / \mathrm{min}$ sampling flowrate. In addition, we also measured real-time air temperature and relative humidity (Vaisala GMW90), concentrations of $\mathrm{CO}_{2}$ (Picarro G2401), $\mathrm{NH}_{3}$ (Picarro G2103), VOCs (PTR-ToFMS 8000), as well as $\mathrm{OH}$ reactivity (customized PTR-MS) inside the chamber. We 
determined $\mathrm{OH}$ concentrations and measured the abundance of squalene in volunteers' skin lipids. Details about the used instruments, placement and procedures can be found in Fig $\mathrm{S} 1$, Section S1 and in Bekö et al. ${ }^{26}$

\section{Data Analysis}

To obtain real-time NCA concentrations, the raw data files from the A11 nCNC were analyzed using customized codes in Scilab 6.1.0 software (ESI Group, France) using the stepwise method. ${ }^{30}$ The data was corrected for particle losses in the sampling tube $(52 \mathrm{~cm})$ due to NCA diffusion onto the tubing wall (penetration efficiency shown in Fig. S2). We further aggregated the number concentrations into five size bins (1.18-1.55, 1.55-1.71, 1.71$1.93,1.93-2.81,2.81-4 \mathrm{~nm})$.

The average emission rate of NCA was calculated based on the material-balance equation inside the chamber:

$V \frac{\mathrm{d} N_{i}}{\mathrm{~d} t}=n E_{i}-\left(\alpha+\beta_{i}+\sum_{i} K_{i} N_{i}\right) N_{i}$

where $N_{i}\left(\mathrm{~cm}^{-3}\right)$ is the particle number concentration for particle size $i ; E_{i}$ (particles per person-h) is the particle number emission rate per person per hour for particle size $i$; $n$ is the number of occupants; $V\left(\mathrm{~cm}^{3}\right)$ is the chamber volume; $\alpha\left(\mathrm{h}^{-1}\right)$ is the air change rate; $\beta\left(\mathrm{h}^{-1}\right)$ is the particle deposition rate obtained via exponential fitting of the particle number concentration during the decay period in each experiment after the volunteers exited the chamber (listed in Table S2, with assumption that the decay rate in the empty chamber represents the deposition rate; see Discussion section); and $\sum_{i} K_{i} N_{i}$ is the net coagulation sink rate $\left(\mathrm{h}^{-1}\right)$ for the particle population consisting of size $i$, determined following the procedure in Wallace et al. ${ }^{9}$ Given the low aerosol particle concentration inside the chamber, the theoretically obtained net coagulation sink rate was as low as $10^{-4}-10^{-3} \mathrm{~h}^{-1},{ }^{9,31}$ which was 
negligible compared to the air change rate and the particle deposition rate. Thus, for steady state conditions, we can obtain the average NCA emission rate in each experiment as:

$$
\bar{E}_{i}=\frac{V}{n}\left(\alpha+\beta_{i}\right) \bar{N}_{i}
$$

where the overbar indicates the average values of $E_{i}$ and $N_{i}$ during the steady state period of occupancy. NCA emission rates were normalized by exposed skin surface area. We estimated the average human body surface area for each group using the height and weight of each volunteer. ${ }^{32} \mathrm{We}$ assigned the exposed skin fractions as $13.8 \%$ and $42.3 \%$ of total body surface area for long and short clothing scenarios, respectively. ${ }^{33}$ The normalized NCA emission rates were obtained by dividing the average emission rates by the exposed skin area.

We analyzed Pearson correlations between NCA emissions and measured concentrations of VOCs, $\mathrm{NH}_{3}$ and $\mathrm{OH}$, as well as $\mathrm{OH}$ reactivity to investigate potential NCA formation mechanisms (Table S3). Mann-Whitney and Kruskal-Wallis tests were performed to examine the dependence of NCA emissions on clothing level and age, respectively. Twotailed test of significance was used.

\section{Results}

\section{Characteristics of NCA emissions}

Fig. 1 shows a time series of ozone mixing ratio and size-dependent NCA number concentrations in the chamber occupied by young adults (group A2) wearing "long" clothing. During the morning when ozone was absent from the chamber, only a brief increase of the NCA concentrations was observed when the volunteers entered and exited the chamber, presumably caused by the intrusion of air from the corridor through the open door $(\sim 5 \mathrm{~s})$. The formation of NCA was observed in the occupied chamber only after ozone 
was introduced in the afternoon, indicating that ozone chemistry was the source of NCA. The ozone concentration inside the occupied chamber reached a steady state value of $\sim 40$ ppb, which was about $40 \%$ of the steady-state ozone concentration in the unoccupied chamber. The concentration of NCA equilibrated at 60 particles $/ \mathrm{cm}^{3}$ one hour after ozone injection began, with $65 \%$ of the measured NCA in the smallest detected size range (1.18 $1.55 \mathrm{~nm})$. When the volunteers exited the chamber, the NCA concentration again demonstrated a sudden peak caused by the open chamber door. Afterwards, it decreased rapidly to zero due to removal by ventilation, deposition and continuous growth, while the ozone concentration increased.

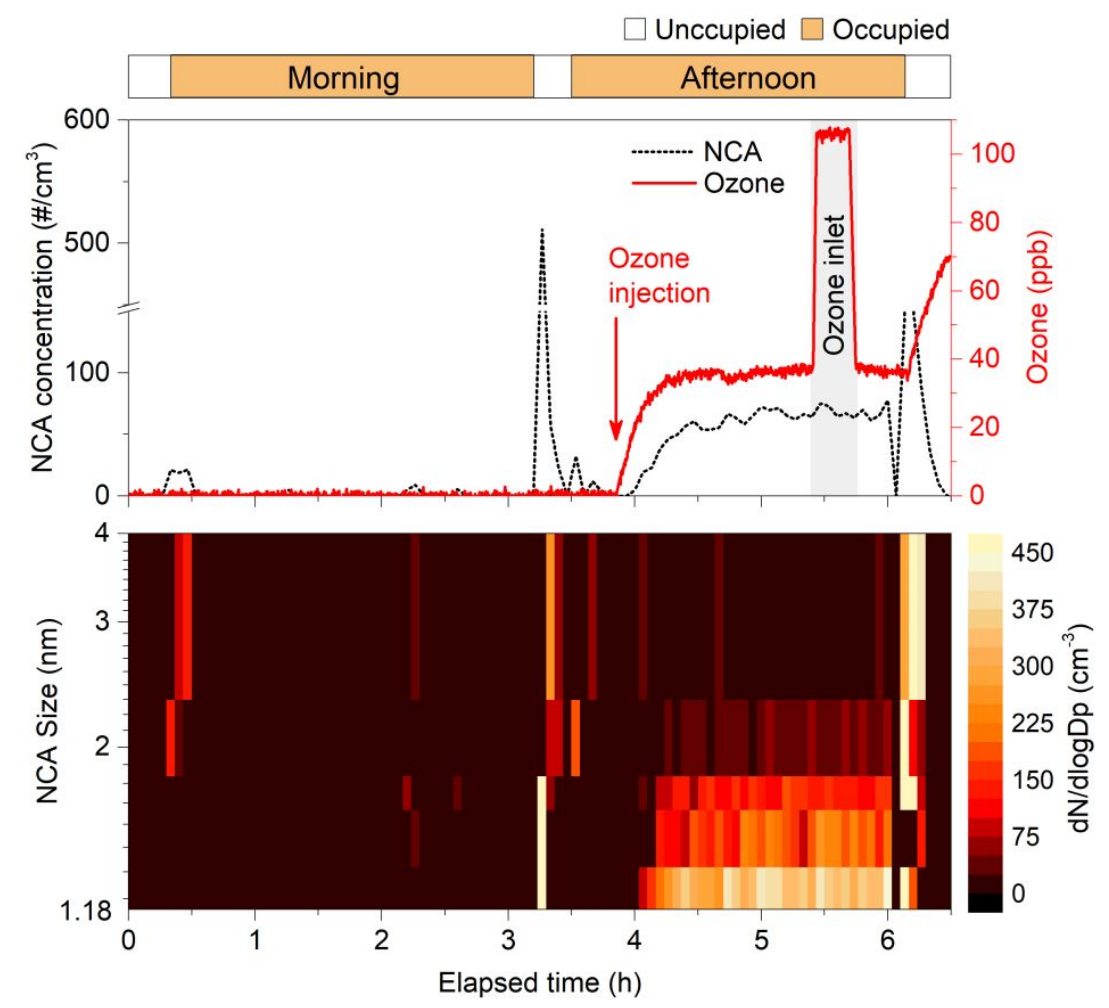

Fig. 1. Time-series of NCA number concentration and ozone (top), and NCA size distribution (bottom). The shown experiment is with young adults (A2) wearing long-sleeve shirts and pants with ozone present from steady state of human emissions (afternoon). During the period with gray background, ozone was sampled in the chamber inlet. The NCA size is activation diameter. 
The formation of NCA began with a time lag relative to the introduction of ozone; it was first detected when the ozone concentration reached $12 \mathrm{ppb}, 8$ minutes after ozone introduction had begun (Fig. S3a). In another experiment, when the volunteers entered the chamber with ozone at steady state (94 ppb), the NCA formation began instantaneously along with the decrease of ozone level inside the chamber (Fig. S3b). Ozone-initiated human emissions of NCA appear to be limited by the ozone concentration and by the presence of reactive species (e.g. squalene) present on the skin of the volunteers. Moreover, the reaction of ozone with the compounds present on the volunteers' skin are kinetically constrained by the resistance to mass transport across the boundary layer of air adjacent to the surface. ${ }^{34}$

The formation of larger size clusters $(2.81-4 \mathrm{~nm})$ also exhibited a time lag relative to the smallest size, 8 minutes after the appearance of 1.18-1.55 $\mathrm{nm}$ aerosols (Fig. 1). The time lag suggests that the larger size NCA were formed by growth from smaller ones. Previous atmospheric nucleation observations found a size-dependent growth rate ranging from 0.2 to $2.1 \mathrm{~nm} / \mathrm{h},{ }^{35}$ though the actual values are not comparable to our experiments due to the difference in environmental and chemical conditions. We can presume that in scenarios of low air change rate and/or densely populated environments, the NCA will reach higher concentrations and subsequently grow over longer timescales to form larger aerosol particles than observed in the present study.

\section{Influencing factors}

The NCA emission rates ranged from $2.4 \times 10^{9}$ to $2.2 \times 10^{10}$ aerosols per person-h, and the exposed-skin-surface-area normalized emission rates were in the range from $9.3 \times 10^{9}$ to $8.8 \times 10^{10}$ aerosols per $\mathrm{h}-\mathrm{m}^{2}$ (Table S1). The NCA emissions did not differ significantly ( $p=0.35$ ) between morning (ozone present from start of experiment) and afternoon (ozone injected after steady state was reached in the chamber) hours. 
Clothing. At similar ozone concentrations in the chamber, young adults emitted about three times more NCA across all size bins when wearing T-shirt and shorts relative to long-sleeve shirt and pants (Fig. 2a). A larger exposed skin surface area provides more opportunity for ozone-skin lipid reactions to occur, and less clothing surface to retain NCA after their release from skin. The skin-surface-area normalized NCA emission rates for experiments with long and short clothing were not significantly different $(p=0.30)$. The substantial influence of clothing on NCA emissions was further demonstrated in a companion experiment with a single bare skinned volunteer in the ozone-laden chamber, who donned long clothing 90 minutes into the experiment (Fig. 2b), substantially decreasing NCA emissions.
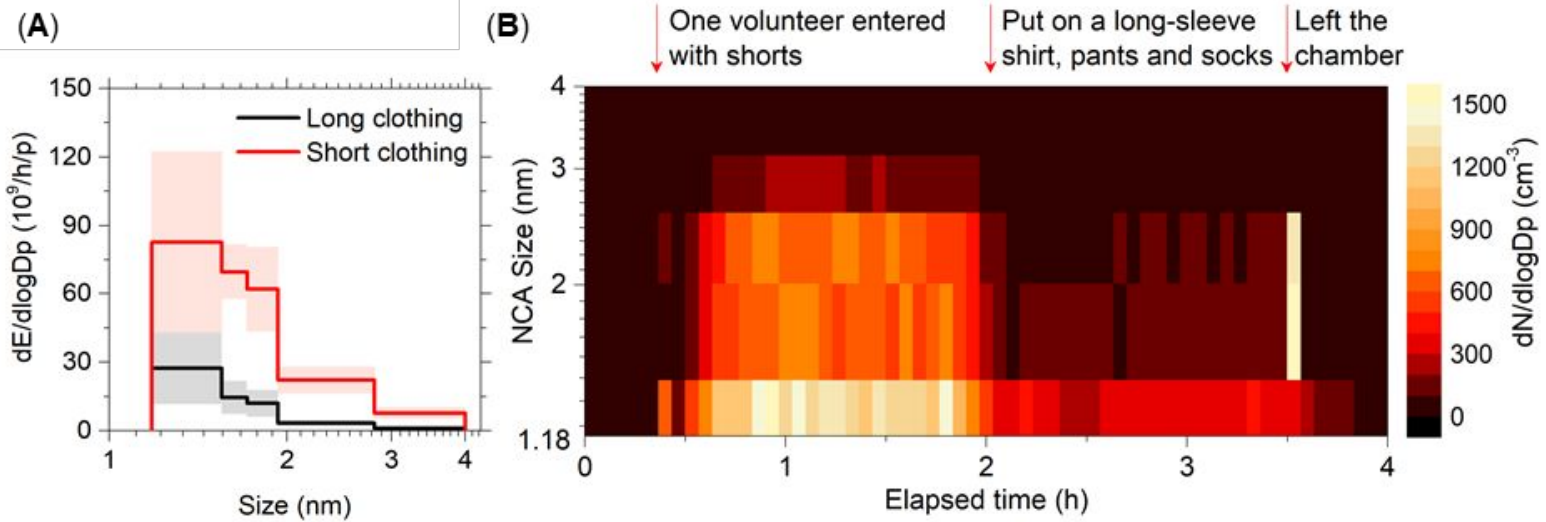

Fig. 2. The influence of clothing on NCA emissions from ozone-human chemistry. (A)

Comparisons of size-resolved NCA emission rates between long and short clothing scenarios. The lines represent averages of all available data within each size bin for the experiments involving young adults A2 $(N=4)$. Shaded areas represent standard deviations; (B) Time-series plot of NCA size distribution in the experiment with one volunteer present in the chamber initially bare skinned (shorts only), then wearing a long-sleeve shirt, pants and socks donned inside the chamber 90 min after entering the chamber. The clothes were kept in sealed plastic bags inside the chamber before wearing. The NCA size is activation diameter. 
Temperature and relative humidity. There was a positive but barely significant correlation between air temperature and normalized NCA emissions (Fig. 3). This may reflect increased ammonia emission rate with temperature, ${ }^{36}$ which will be discussed later. The rate of increase in NCA emission with a unit change in temperature decreased with increasing particle size. Increasing temperature generally accelerates chemical reactions in
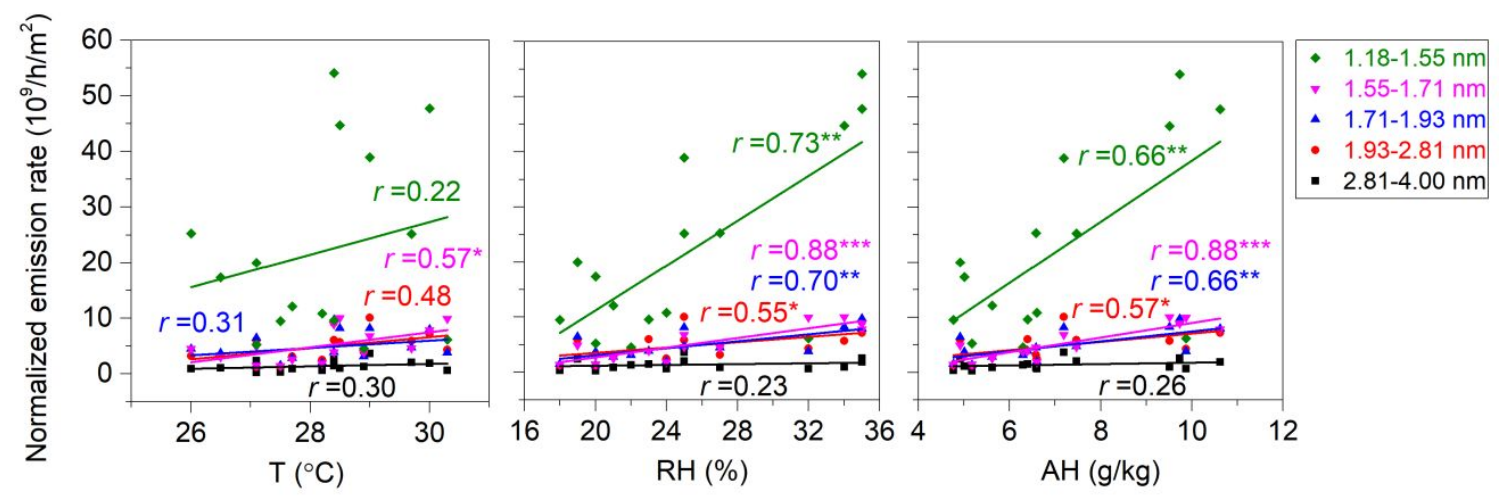
Fig. 3. Pearson correlation between temperature (T), relative humidity (RH) and absolute humidity (AH), and exposed skin-surface-area normalized NCA emission rates for the different NCA size bins. ${ }^{*} p<0.05 ; * * p<0.01 ; * * * p<0.001$

Age. Teenagers exposed to ozone emitted about $2-3 \times$ more NCA than seniors and young

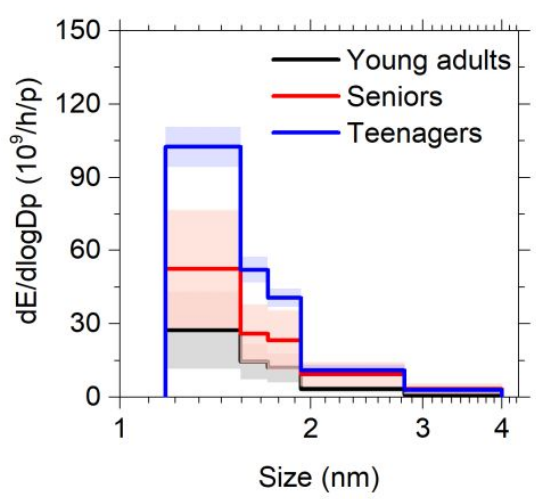

Fig. 4. Influence of age on NCA emissions from ozone-human chemistry. The lines represent averages of all available data within each size bin for the experiments involving young adults $\mathrm{A} 2(N=4)$, seniors $\mathrm{S} 5(N=3)$, and teenagers $\mathrm{T} 4(N=3)$, all wearing long clothing. Shaded areas represent standard deviations. The NCA size is activation diameter. 


\section{$311 \quad$ Discussion}

\section{Potential mechanisms of NCA formation}

Ozone reacts with chemical constituents of exhaled air, ${ }^{43}$ skin lipids, ${ }^{18}$ personal care products $^{44}$ and clothing fabric ${ }^{19,22}$. The use of personal care products was strictly limited in this study, so its contribution to the NCA formation was negligible. Human exhaled air contains isoprene, ${ }^{43}$ which can react with ozone to form secondary organic aerosols albeit at relatively low yield. ${ }^{45}$ However, the pseudo-first order rate constant for this reaction is much smaller than the ventilation rate used in our experiments $\left(0.04 \mathrm{~h}^{-1}\right.$ vs. $\left.3.2 \mathrm{~h}^{-1}\right)$. During a companion experiment to investigate the ozone reaction with human exhaled air, the volunteers were seated in the neighboring auxiliary chamber and exhaled through breathing masks into the primary chamber where the measurements took place. ${ }^{26}$ Ozone concentration reached a stable level at $\sim 90 \mathrm{ppb}$ soon after its generation began. Indeed, we did not detect NCA during the co-occurring presence of ozone and exhaled air.

The liquid crystal display (LCD) screens of used smartphones and tablets can also emit unsaturated VOCs, albeit at considerably lower rate relative to humans. ${ }^{46}$ Four tablets were continuously present inside the chamber, including during ozone-rich unoccupied periods. No NCA signals were detected during this time. In addition, the pseudo-first order rate constants of LCD-emitted unsaturated VOCs were significantly lower than the air change rate $\left(<0.1 \mathrm{~h}^{-1}\right.$ vs. $\left.3.2 \mathrm{~h}^{-1}\right) .{ }^{46}$ Therefore, it is unlikely that the VOC emissions from LCD screens of the devices contributed to NCA emissions in this study. While the reactions of ozone with the surface of clean clothing (without human present) can produce VOCs, ${ }^{19}$ they did not generate NCA (Fig. S4). On the other hand, when previously worn clothing containing skin lipids was placed in the chamber in the presence of ozone, a clear NCA signal was detected (Fig. S4). These observations strongly suggest that ozone reactions with human skin lipids are responsible for the observed NCA emissions. 
Skin lipids contain organic compounds such as squalene and unsaturated fatty acids, ${ }^{47}$ which

can react rapidly with ozone by virtue of their double bonds. The ozonolysis products include gaseous compounds (e.g. acetone, geranyl acetone, 6-methyl-5-hepten-2-one (6MHO), 4-oxopentanal (4OPA), hexanal and decanal), as well as compounds with low volatility (C17-trienoic acid, C17-trienal, C22-tetraenoic acid). ${ }^{18}$ Based on prior studies, ${ }^{48-}$ ${ }^{50}$ we anticipate that these low-volatility products generated by reactions of ozone with unsaturated skin lipids contribute to the formation of NCA. We quantified squalene in the skin wipe samples collected from six volunteers. The mostly positive correlations between the amount of squalene in skin wipes and skin-surface-area normalized NCA emission rates (Fig. S5) further underline the assumption that the ozonolysis of organic compounds present in skin lipids is the major driving mechanism of the NCA formations.

Fig. 5 shows that the NCA emissions in most size ranges significantly positively correlated with the steady state concentrations of the ozonolysis products acetic acid, 4OPA, 6MHO, $\mathrm{OH}-6 \mathrm{MHO}$ and decanal across all experiments. Also shown is a plot for a $\mathrm{C}_{18} \mathrm{H}_{32}$ hydrocarbon that demonstrated a negative correlation with NCA emissions. This is just one example from a series including $\mathrm{C}_{17} \mathrm{H}_{n}, \mathrm{C}_{18} \mathrm{H}_{n}, \mathrm{C}_{19} \mathrm{H}_{\mathrm{n}}$, and $\mathrm{C}_{20} \mathrm{H}_{\mathrm{n}}$ hydrocarbons that all anticorrelated with NCA emissions (see Table S3). The PTR-ToF-MS identifies only the molecular formula based on the exact mass determination of these species; we are unable to identify their structures unequivocally. They could be unsaturated linear, branched or cyclic hydrocarbons. Alternatively, they could be fragments produced when water is lost from protonated oxygenated precursors. We suspect the latter (fragments of oxygenated precursors), since the corresponding saturated hydrocarbons $\left(\mathrm{C}_{17} \mathrm{H}_{36}, \mathrm{C}_{18} \mathrm{H}_{38}, \mathrm{C}_{19} \mathrm{H}_{40}\right.$, or $\mathrm{C}_{20} \mathrm{H}_{42}$ ) were not identified. Furthermore, in an ozone-rich environment, a fragment of an oxidation product makes more sense than an unsaturated hydrocarbon (which would react with ozone). Regardless, a larger concentration of NCA in the chamber translates to a larger 
fraction of $\mathrm{C} 17, \mathrm{C} 18, \mathrm{C} 19$, and $\mathrm{C} 20$ organic compounds partitioning onto NCA, lowering

the gas-phase concentrations of these low volatility species as measured by the PTR-ToF-

MS. The full correlation matrix for the NCA emissions and detected gas-phase organic compounds is presented in Table S3.
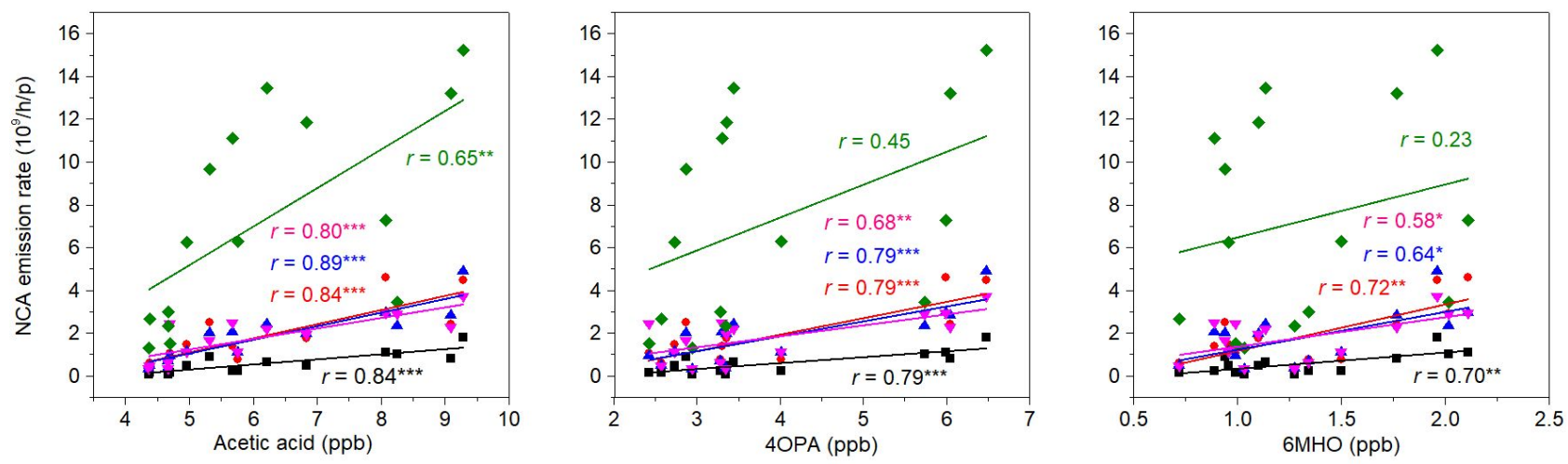

- $1.18-1.55 \mathrm{~nm}$

$\checkmark \quad 1.55-1.71 \mathrm{~nm}$

- $1.71-1.93 \mathrm{~nm}$

- $1.93-2.81 \mathrm{~nm}$

- $2.81-4.00 \mathrm{~nm}$
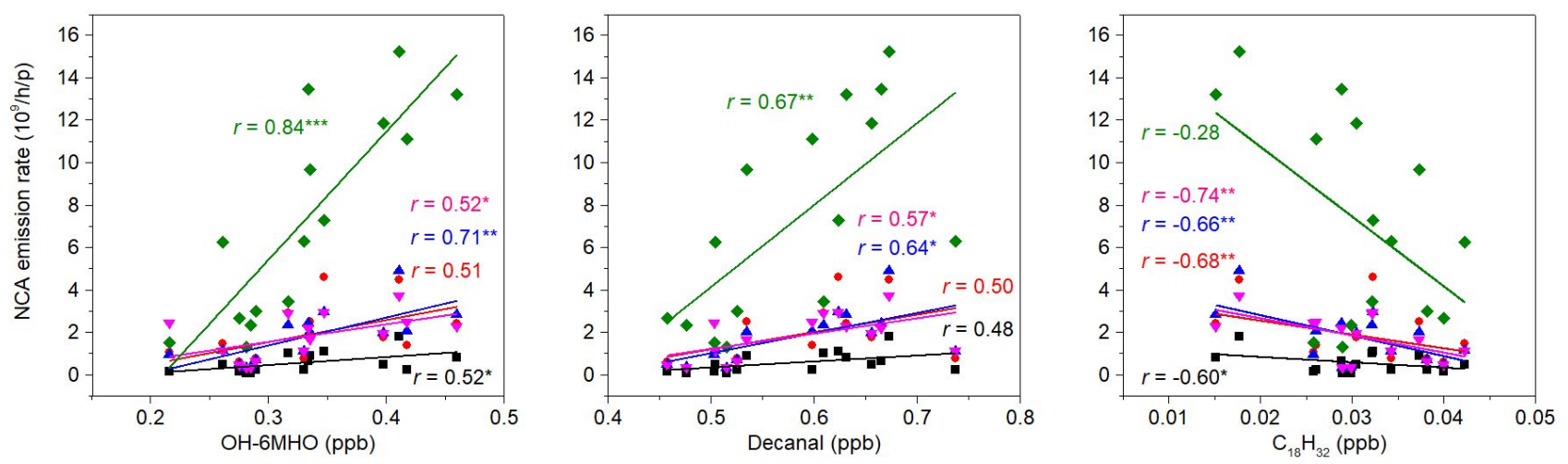

Fig. 5. Pearson correlations between steady state concentrations of selected organic compounds (acetic acid, 4OPA, 6MHO, OH-6MHO, decanal, and a compound or fragment with molecular formula $\mathrm{C}_{18} \mathrm{H}_{32}$ ) and NCA emissions of different sizes across all experiments. ${ }^{*} p<0.05 ; * * p<0.01 ; * * * p<0.001$

Some primary products of skin lipid ozonolysis contain unsaturated carbon-carbon bonds that can subsequently react with ozone and form secondary products. For example, $6 \mathrm{MHO}$ and $\mathrm{OH}-6 \mathrm{MHO}$ originate from both primary and secondary chemistry, while 4OPA is a product of secondary ozone reactions only (Fig. S6).${ }^{18}$ Fig. 6 shows an example of a time 
series for primary and secondary reaction products along with ozone and NCA concentrations. The concentration of $6 \mathrm{MHO}$ followed the pattern of ozone concentrations, reaching steady state $\sim 1 \mathrm{~h}$ after ozone dosing began. In contrast, the concentration of $4 \mathrm{OPA}$ increased during the course of the experiment and did not reach steady state. The NCA curve in Fig. 6 is shaped similar to that of ozone, reaching steady state $\sim 0.5 \mathrm{~h}$ after initiation. Additionally, NCA concentrations correlated better with the concentrations of $6 \mathrm{MHO}$ than 4OPA (correlation coefficient: 0.98 vs. 0.87 ). This suggests that for NCA formation in these experiments, primary ozone-skin lipid chemistry may be of more importance than secondary chemistry, which takes longer to attain steady state.

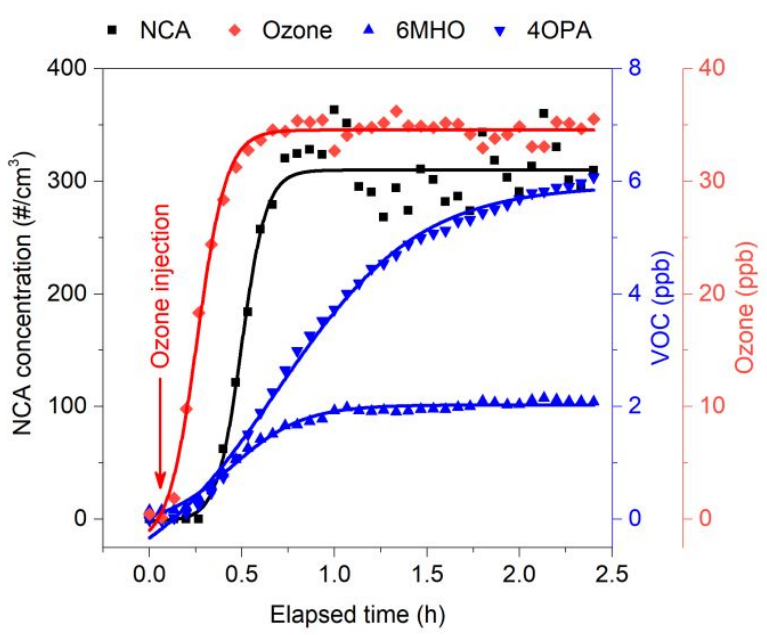

Fig. 6. Time series of NCA, ozone, $6 \mathrm{MHO}$ and $4 \mathrm{OPA}$ concentrations. Data are from the experiment with young adults (A2) wearing T-shirts and shorts with ozone dosed after human emissions reached steady state (afternoon). Boltzmann equation was applied for curve fitting (solid lines).

Primary ozone-initiated chemistry takes place mainly on the surfaces of the skin and worn clothing. Secondary reactions occur both on the surfaces and in the gas phase. After the volunteers exited the chamber, ozone concentration increased and the concentrations of the gas-phase reaction products and $\mathrm{CO}_{2}$ decreased. The decay rates of these compounds varied. 
The concentration of $6 \mathrm{MHO}$ decayed much faster than $\mathrm{CO}_{2}$; neither compound had sources present, and $6 \mathrm{MHO}$ continued to react with ozone. Lower decay rates were observed for 4OPA and acetic acid, reflecting the fact that these compounds continued to be formed by residual reactions (Fig. S7). However, it remains uncertain whether the residual reactions generated NCA, as the clusters quickly disappeared (large decay rates). It is therefore also unclear whether the decay rates reliably reflect NCA deposition loss rates (Table S2), although the values were within the range reported from theoretical calculations (Fig. S8). ${ }^{51}$ The relative contribution of surface reactions and gas-phase reactions to the observed NCA warrants further investigation.

Another means of producing NCA is through $\mathrm{OH}$ radical oxidation. Criegee intermediates formed during ozonolysis decompose to produce $\mathrm{OH}$ radicals. ${ }^{52} \mathrm{OH}$ radicals can oxidize saturated as well as unsaturated organic compounds at a rapid rate. Reactions occur both in the gas phase and on surfaces, and can produce products with volatilities lower than those of the precursors, ${ }^{49,53}$ contributing to the formation of secondary organic aerosols (SOA) ${ }^{54}$ Interestingly, the normalized NCA emissions were negatively correlated with $\mathrm{OH}$ concentration in the chamber (Table S3). When ozone reacts with human skin surface lipids, Criegee intermediates that might otherwise have decomposed to yield $\mathrm{OH}$ radicals may instead react with aldehydes and acids produced by the ozone/skin oil chemistry. The consequent hydroperoxides may play a role in NCA formation. Alternatively, NCA formation may consume $\mathrm{OH}$ at a faster rate relative to the production of $\mathrm{OH}$ during ozonolysis. Regardless, significant positive correlations were found between skin-surfacearea normalized NCA emissions and total $\mathrm{OH}$ reactivity (Table S3), as both increase with increasing ozone-human interaction.

Humans are substantial emitters of ammonia $\left(\mathrm{NH}_{3}\right)$, in particular through the skin. Throughout the experiments, we observed significant $\mathrm{NH}_{3}$ emissions from the volunteers; 
emission rates were higher at elevated temperatures and with larger unclothed skin surface area. ${ }^{36}$ Previous studies have indicated that the presence of $\mathrm{NH}_{3}$ can enhance SOA formation resulting from ozone-terpene reactions. ${ }^{55,56}$ This has been interpreted as the stabilization of the initial molecular cluster against separation by the presence of ammonia. ${ }^{57}$ Gas-phase reactions between $\mathrm{NH}_{3}$ and mono-, oxo-, and dicarboxylic acids, formed when ozone reacts with squalene and unsaturated fatty acids in human skin oil, ${ }^{18}$ may contribute to NCA via formation of condensable salts. Amines, although present at concentrations several orders of magnitude lower than $\mathrm{NH}_{3}$, may also play a role. ${ }^{25,35,58}$ Emissions of NCA in several size bins were significantly positively correlated with glycine $\left(\mathrm{C}_{2} \mathrm{H}_{5} \mathrm{NO}_{2}\right)$, succinimide $\left(\mathrm{C}_{4} \mathrm{H}_{5} \mathrm{NO}_{2}\right)$ and cyclohexyl-prop-2-ynyl-amine $\left(\mathrm{C}_{9} \mathrm{H}_{15} \mathrm{~N}\right.$, Table $\left.\mathrm{S} 3\right)$. Such a chemical process involving acids and $\mathrm{NH}_{3}$ /amines has been identified as an important pathway to form atmospheric clusters. ${ }^{59,60}$

The concentration of nitric oxide (NO) was expected to be low during these chamber experiments, especially when ozone was present. Under such conditions the lifetimes of alkylperoxy radicals $\left(\mathrm{RO}_{2} \bullet\right)$, derived from ozone-initiated chemistry, are relatively long and autoxidation reactions can generate highly oxidized multifunctional compounds (HOMs) ${ }^{61}$ Autoxidation of limonene has recently been reported to occur in a university art museum when NO concentrations were low. ${ }^{62}$ Furthermore, Criegee intermediates formed during ozonolysis, have been shown to propagate chain reactions in the autoxidation of unsaturated lipids. ${ }^{63}$ Autoxidation reactions and consequent HOMs are still another potential contributor to the formation of NCA observed in the present study, as has been found in the atmosphere. ${ }^{60}$

The aforementioned chemistry is associated most closely with aerosols of the smallest size bin, as larger clusters are likely to originate from growth of the smaller ones via physical process such as coagulation and condensation. If we assume, for example, OH-geranyl 
acetone $\left(\mathrm{C}_{13} \mathrm{H}_{22} \mathrm{O}_{2}\right.$, one of the squalene ozonolysis products) as a constituent of the formed clusters, the 1.18-1.55 nm NCA would be formed by 3-4 compound molecules, whereas 4 and 12 times more molecules are required to form 2-3 nm and 3-4 nm clusters, respectively (see Section S2 for details). This may also explain the higher concentrations in the smaller size bins and the delayed signals of larger clusters shown in Fig. 1. Future research is warranted to investigate the chemical and physical processes, in both particle and gas phase, involved in the growth of NCA generated in ozone-human chemistry over longer residence times than those accessed at this ventilation rate.

\section{Limitations}

Replicate experiments demonstrated reasonable reproducibility of the results (mostly within $40 \%$ ) considering the factors influencing the measurements. The exceptions were the experiments on 8 and 10 April, where a 4-fold difference in the normalized NCA emission rate was observed. NCA concentrations as low as in this study (10 to 100 aerosols $\left./ \mathrm{cm}^{3}\right)$ are sensitive to small differences in the available precursors (skin lipids and ozone), the possible air disturbances induced by human volunteers in the chamber, the state of the chamber surfaces, and the overall initial conditions. Furthermore, uncertainties associated with the NCA measurement instrument should also be considered, which were around $50 \%$ given the concentrations. ${ }^{6}$ As proposed by Chan et al. ${ }^{64}$ the stepwise data inversion method used in this study might result in overestimated sub-3 nm NCA concentrations in scenarios with high concentrations of larger particles and strong concentration fluctuations. However, given the stable NCA concentrations (Fig. 1) and low 10-1000 nm particle levels (Fig. S9) in this study, uncertainties associated with the data inversion method are expected to be negligible. The limit of detection for the 14 VOCs for which the PTR-ToF-MS was calibrated with a gas standard ranged from $7 \mathrm{ppt}$ to $171 \mathrm{ppt}$. Other VOCs were quantified with an accuracy around 50\%. See Wang et al. ${ }^{65}$ for additional details on the accuracy of 
the chemical measurements. Another limitation of this study is the lack of continuous aerosol size distribution measurements beyond the NCA mode (4-10 nm). Future measurements should comprehensively cover the relevant particle size range in order to study the growth of NCA particles into larger sizes and the associated particle dynamics.

\section{Implications and future outlook}

Humans significantly contribute to the chemical and particulate composition of indoor environments. Ozone-initiated chemical transformations play an important role in this. We observed for the first time the formation of single-digit nanometer size aerosols resulting from ozone-human chemistry. Although the NCA emission rates from ozone chemistry continuously occurring on humans in this study were 2-3 orders of magnitude lower than from other known sporadic indoor NCA sources, including cooking ${ }^{7}$ and $3 \mathrm{D}$ printers, ${ }^{10}$ the results provide new insights into NCA formation in our immediate vicinity when encountering ozone. The findings highlight the interconnected nature of gas-phase and particle-phase components of indoor air, as well as their dynamics. Further investigations into the chemical processes driving NCA formation are warranted, especially over longer residence times, including the contribution of primary and secondary reactions, the role of $\mathrm{OH}$ radicals, $\mathrm{NH}_{3}$ and other chemicals, as well as the fate of the resulting $\mathrm{NCA}$.

The present study was performed in a well-controlled stainless-steel climate chamber with efficient filtration. The air in real indoor environments contains various additional organic and inorganic compounds in both the gas phase and on surfaces. Some of these are anticipated to participate in the formation of NCA and alter the properties of the newly formed aerosols. Furthermore, skin oils and their chemical constituents can be found on various indoor surfaces, such as glass, carpet and settled dusts. ${ }^{66,67} \mathrm{NCA}$ formation from human-ozone interaction may therefore be substantially more pronounced in real indoor 
environments. On the other hand, the presence of other aerosol sources could act as larger coagulation/condensation sinks for the NCA and gas-phase precursors, and thus limit the nucleation of NCA in real indoor environments. Therefore, the formation of NCA in indoor environments is likely a complex multigenerational process, the understanding of which requires further investigations.

The approximately $100 \mathrm{ppb}$ inlet ozone concentration, analogous to the ozone concentration outside a building, is similar to what might occur during a pollution episode in an urban area on a hot day. The $\sim 40 \mathrm{ppb}$ ozone level in the occupied chamber has been measured in buildings with high ventilation rates during ozone pollution episodes. ${ }^{68}$ It should be noted that indoor ozone levels are strongly dependent on outdoor ozone concentrations, ventilation, and indoor ozone sources/sinks, ${ }^{69,70}$ and thus vary in indoor environments. ${ }^{71}$ Future research on the influence of ozone concentration on human derived NCA emissions is warranted.

\section{Supporting Information}

Details of measurement instruments and procedures (Section S1); estimation of the number of molecules constituting NCA of different sizes (Section S2); schematic layout of the unoccupied environmental chamber with sampling locations; penetration efficiency due to particle diffusional losses in the sampling tube; time-series of NCA number concentrations and ozone in the experiment; time-series of NCA distribution in the chamber with ozone 
and either new or worn clothing; Pearson correlation between squalene in skin wipes and NCA emission rates across different NCA size ranges; example of primary and secondary reactions during squalene ozonolysis; decay rates of acetic acid, $4 \mathrm{OPA}, 6 \mathrm{MHO}, \mathrm{CO}_{2}$, and NCA; comparison between obtained NCA decay rates and those in earlier theoretical calculations; steady-state 1-1000 nm particle size distribution; summary of experimental conditions and associated NCA number concentrations and emission rates; empirically derived size-resolved decay rates; Pearson correlations between NCA emission rates and steady state VOC concentrations, $\mathrm{OH}$ reactivity, $\mathrm{OH}$ concentrations and $\mathrm{NH} 3$ concentrations.

\section{Acknowledgments}

The study was funded by the Alfred P. Sloan Foundation Grant No. G-2018-11233 and by École Polytechnique Fédérale de Lausanne (EPFL). We thank the volunteers for their participation in this study, and Nico Ziersen for his technical help with the climate chamber.

Competing interests: Authors declare that they have no competing interests.

\section{References}

1. Rönkkö, T.; Kuuluvainen, H.; Karjalainen, P.; Keskinen, J.; Hillamo, R.; Niemi, J. v.; Pirjola, L.; Timonen, H. J.; Saarikoski, S.; Saukko, E.; Järvinen, A.; Silvennoinen, H.; Rostedt, A.; Olin, M.; Yli-Ojanperä, J.; Nousiainen, P.; Kousa, A.; Dal Maso, M. Traffic is a major source of atmospheric nanocluster aerosol. Proc. Natl. Acad. Sci. U. S. A. 2017, 114, 75497554.

2. Jokinen, T.; Sipilä, M.; Kontkanen, J.; Vakkari, V.; Tisler, P.; Duplissy, E.-M.; Junninen, H.; Kangasluoma, J.; Manninen, H. E.; Petäjä, T.; Kulmala, M.; Worsnop, D. R.; Kirkby, J.; Virkkula, A.; Kerminen, V.-M. Ion-induced sulfuric acid-ammonia nucleation drives particle formation in coastal Antarctica. Sci. Adv. 2018, 4, eaat9744. 
$540 \quad$ 3. Kontkanen, J.; Lehtipalo, K.; Ahonen, L.; Kangasluoma, J.; Manninen, H. E.; Hakala, 541 J.; Rose, C.; Sellegri, K.; Xiao, S.; Wang, L.; Qi, X.; Nie, W.; Ding, A.; Yu, H.; Lee, S.; 542 Kerminen, V.-M.; Petäjä, T.; Kulmala, M. Measurements of sub-3 nm particles using a particle 
5639 9. Wallace, L.; Jeong, S.; Rim, D. Dynamic behavior of indoor ultrafine particles (2.3-64

$564 \mathrm{~nm}$ ) due to burning candles in a residence. Indoor Air 2019, 29, 1018-1027.

565 10. Poikkimäki, M.; Koljonen, V.; Leskinen, N.; Närhi, M.; Kangasniemi, O.; Kausiala, 566 O.; Dal Maso, M. Nanocluster aerosol emissions of a 3D printer. Environ. Sci. Technol. 2019, $567 \quad 53,13618-13628$.

$568 \quad$ 11. Wallace, L. A.; Ott, W. R.; Weschler, C. J.; Lai, A. C. K. Desorption of SVOCs from 569 heated surfaces in the form of ultrafine particles. Environ. Sci. Technol. 2017, 51, 1140-1146.

570 12. Schraufnagel, D. E. The health effects of ultrafine particles. Exp. Mol. Med. 2020, 52, $571 \quad 311-317$

13. Carnerero, C.; Pérez, N.; Petäjä, T.; Laurila, T. M.; Ahonen, L. R.; Kontkanen, J.; Ahn, K.-H.; Alastuey, A.; Querol, X. Relating high ozone, ultrafine particles, and new particle formation episodes using cluster analysis. Atmos. Environ.: X, 2019, 4, 100051.

14. Nazaroff, W. W.; Weschler, C. J.; Corsi, R. L. Indoor air chemistry and physics. Atmos. Environ. 2003, 37, 5451-5453.

15. Yang, S.; Perret, V.; Hager Jörin, C.; Niculita-Hirzel, H.; Goyette Pernot, J.; Licina, D. Volatile organic compounds in 169 energy-efficient dwellings in Switzerland. Indoor Air 2020, $30,481-491$.

16. Weschler, C. J.; Carslaw, N. Indoor Chemistry. Environ. Sci. Technol. 2018, 52, 24192428.

17. Weschler, C. J. Roles of the human occupant in indoor chemistry. Indoor Air 2016, 26, $6-24$. 
584 18. Wisthaler, A.; Weschler, C. J. Reactions of ozone with human skin lipids: Sources of carbonyls, dicarbonyls, and hydroxycarbonyls in indoor air. Proc. Natl. Acad. Sci. U. S. A. 2010, 107, 6568-6575.

19. Yang, S.; Gao, K.; Yang, X. Volatile organic compounds (VOCs) formation due to interactions between ozone and skin-oiled clothing: Measurements by extraction-analysisreaction method. Build. Environ. 2016, 103, 146-154.

20. Arata, C.; Heine, N.; Wang, N.; Misztal, P. K.; Wargocki, P.; Bekö, G.; Williams, J.; Nazaroff, W.W; Wilson, K. R.; Goldstein A. H. Heterogeneous ozonolysis of squalene: Gasphase products depend on water vapor concentration. Environ. Sci. Technol. 2019, 53, 1444114448.

21. Zhou, S.; Forbes, M. W.; Abbatt, J. P. D. Kinetics and products from heterogeneous oxidation of squalene with ozone. Environ. Sci. Technol. 2016, 50, 11688-11697.

22. Rai, A. C.; Guo, B.; Lin, C.-H.; Zhang, J.; Pei, J.; Chen Q. Ozone reaction with clothing and its initiated particle generation in an environmental chamber. Atmos. Environ. 2013, 77, 885-892.

23. Xiang, J.; Weschler, C. J.; Mo, J.; Day, D.; Zhang, J.; Zhang, Y. Ozone, electrostatic precipitators, and particle number concentrations: correlations observed in a real office during working hours. Environ. Sci. Technol. 2016, 50, 10236-10244.

24. Stolzenburg, D.; L. Fischer; A. L. Vogel; M. Heinritzi; M. Schervish; M. Simon; A. C. Wagner; L. Dada; L. R. Ahonen; A. Amorim; A. Baccarini; P. S. Bauer; B. Baumgartner; A. Bergen; F. Bianchi; M. Breitenlechner; S. Brilke; S. B. Mazon; D. Chen; A. Dias; D. C. Draper; J. Duplissy; I. el Haddad; H. Finkenzeller; C. Frege; C. Fuchs; O. Garmash; H. Gordon; X. He; J. Helm; V. Hofbauer; C. R. Hoyle; C. Kim; J. Kirkby; J. Kontkanen; A. Kürten; J. Lampilahti; M. Lawler; K. Lehtipalo; M. Leiminger; H. Mai; S. Mathot; B. Mentler; U. Molteni; W. Nie; 
608 T. Nieminen; J. B. Nowak; A. Ojdanic; A. Onnela; M. Passananti; T. Petäjä; L. L. J. Quéléver; 609 M. P. Rissanen; N. Sarnela; S. Schallhart; C. Tauber; A. Tomé; R. Wagner; M. Wang; L. Weitz; 610 D. Wimmer; M. Xiao; C. Yan; P. Ye; Q. Zha; U. Baltensperger; J. Curtius; J. Dommen; R. C. 611 Flagan; M. Kulmala; J. N. Smith; D. R. Worsnop; A. Hansel; N. M. Donahue; P. M. Winkler. 612 Rapid growth of organic aerosol nanoparticles over a wide tropospheric temperature range. 613 Proc. Natl. Acad. Sci. U. S. A. 2018, 115, 9122-9127.

25. Wang, M.; W. Kong; R. Marten; X. C. He; D. Chen; J. Pfeifer; A. Heitto; J. Kontkanen;

L. Dada; A. Kürten; T. Yli-Juuti; H. E. Manninen; S. Amanatidis; A. Amorim; R. Baalbaki; A. Baccarini; D. M. Bell; B. Bertozzi; S. Bräkling; S. Brilke; L. C. Murillo; R. Chiu; B. Chu; L. P. de Menezes; J. Duplissy; H. Finkenzeller; L. G. Carracedo; M. Granzin; R. Guida; A. Hansel; V. Hofbauer; J. Krechmer; K. Lehtipalo; H. Lamkaddam; M. Lampimäki; C. P. Lee; V. Makhmutov; G. Marie; S. Mathot; R. L. Mauldin; B. Mentler; T. Müller; A. Onnela; E. Partoll; T. Petäjä; M. Philippov; V. Pospisilova; A. Ranjithkumar; M. Rissanen; B. Rörup; W. Scholz; J. Shen; M. Simon; M. Sipilä; G. Steiner; D. Stolzenburg; Y. J. Tham; A. Tomé; A. C. Wagner; D. S. Wang; Y. Wang; S. K. Weber; P. M. Winkler; P. J. Wlasits; Y. Wu; M. Xiao; Q. Ye; M. Zauner-Wieczorek; X. Zhou; R. Volkamer; I. Riipinen; J. Dommen; J. Curtius; U. Baltensperger; M. Kulmala; D. R. Worsnop; J. Kirkby; J. H. Seinfeld; I. El-Haddad; R. C. Flagan; N. M. Donahue. Rapid growth of new atmospheric particles by nitric acid and ammonia condensation. Nature 2020, 581, 184-189

26. Bekö, G.; Wargocki, P.; Wang, N.; Li, M.; Weschler, C. J.; Morrison, G.; Langer, S.; Ernle, L.; Licina, D.; Yang, S.; Zannoni, N.; Williams J. The Indoor Chemical Human Emissions and Reactivity (ICHEAR) project: Overview of experimental methodology and preliminary results. Indoor Air 2020, 30, 1213-1228. 
631 27. Yang, S.; Bekö, G.; Wargocki, P.; Williams, J.; Licina, D. Human emissions of sizeresolved fluorescent aerosol particles: Influence of personal and environmental factors. Environ. Sci. Technol. 2021, 55, 509-518.

28. Vanhanen, J.; Mikkilä, J.; Lehtipalo, K.; Sipilä, M.; Manninen, H. E.; Siivola, E.; Petäjä, T.; Kulmala, M. Particle size magnifier for nano-CN detection. Aerosol Sci. Technol. 2011, 45, 533-542.

29. McMurry, P. H. The history of condensation nucleus counters. Aerosol Sci. Tech. 2000, $33(4), 297-322$.

30. Lehtipalo, K.; Leppa, J.; Kontkanen, J.; Kangasluoma, J.; Franchin, A.; Wimnner, D.; Schobesberger, S.; Junninen, H.; Petaja, T.; Sipila, M.; Mikkila, J. Methods for determining particle size distribution and growth rates between 1 and $3 \mathrm{~nm}$ using the Particle Size Magnifier. Boreal Environ. Res. 2014, 19, 215-536.

31. Alam, M. K. The effect of van der Waals and viscous forces on aerosol coagulation. Aerosol Sci. Technol. 1987, 6, 41-52.

32. du Bois, D.; du Bois, E. F. A formula to estimate the approximate surface area if height and weight be known. Arch. Intern. Med. 1916, 17, 863-871.

33. Lee, J.-Y.; Choi, J.-W. Estimation of regional body surface area covered by clothing. J. Hum. Environ. Stud. 2009, 12, 35-45.

34. Salvador, C. M.; Bekö, G.; Weschler, C. J.; Morrison, G.; le Breton, M.; Hallquist, M.; Ekberg, L.; Langer, S. Indoor ozone/human chemistry and ventilation strategies. Indoor Air, 2019, 29, 913-925.

35. Kulmala, M.; J. Kontkanen; H. Junninen; K. Lehtipalo; H. E. Manninen; T. Nieminen; T. Petäjä; M. Sipilä; S. Schobesberger; P. Rantala; A. Franchin; T. Jokinen; E. Järvinen; M. Äijälä; J. Kangasluoma; J. Hakala; P. P. Aalto; P. Paasonen; J. Mikkilä; J. Vanhanen; J. Aalto; 

H. Hakola; U. Makkonen; T. Ruuskanen; R. L. Mauldin; J. Duplissy; H. Vehkamäki; J. Bäck; A. Kortelainen; I. Riipinen; T. Kurtén; M. v. Johnston; J. N. Smith; M. Ehn; T. F. Mentel; K. E. J. Lehtinen; A. Laaksonen; V. M. Kerminen; D. R. Worsnop. Direct observations of atmospheric aerosol nucleation. Science 2013, 339, 943-946.

36. Li, M.; Weschler, C. J.; Bekö, G.; Wargocki, P.; Lucic, G.; Williams, J. Human ammonia emission rates under various indoor environmental conditions. Environ. Sci. Technol. 2020, 54, 5419-5428.

37. Zeng, G.; Holladay, S.; Langlois, D.; Zhang, Y.; Liu, Y. Kinetics of heterogeneous reaction of ozone with linoleic acid and its dependence on temperature, physical state, $\mathrm{RH}$, and ozone concentration. J. Phys. Chem. A. 2013, 117, 1963-1974.

38. Chen, H.; Finlayson-Pitts, B. J. New particle formation from methanesulfonic acid and amines/ammonia as a function of temperature. Environ. Sci. Technol. 2017, 51, 243-252.

39. Sheehan, P. E.; Bowman, F. M. Estimated effects of temperature on secondary organic aerosol concentrations. Environ. Sci. Technol. 2001, 35, 2129-2135 (2001).

40. Heine, N.; Houle, F. A.; Wilson, K. R. Connecting the elementary reaction pathways of Criegee intermediates to the chemical erosion of squalene interfaces during ozonolysis. Environ. Sci. Technol. 2017, 51, 13740-13748.

41. Manuskiatti, W.; Schwindt, D. A.; Maibach, H. I. Influence of age, anatomic site and race on skin roughness and scaliness. Dermatology 1998, 196, 401-407.

42. Nazzaro-Porro, M.; Passi, S.; Boniforti, L.; Belsito, F. Effects of aging on fatty acids in skin surface lipids. J. Invest. Dermatol. 1979, 73, 112-117.

43. Sun, X.; He, J.; Yang, X. Human breath as a source of VOCs in the built environment, Part I: A method for sampling and detection species. Build. Environ. 2017, 125, 565-573. 
44. Corsi, R. L.; Siegel, J.; Karamalegos, A.; Simon, H.; Morrison, G. C. Personal reactive clouds: Introducing the concept of near-head chemistry. Atmos. Environ. 2007, 41, 3161-3165.

45. Kleindienst, T. E.; Lewandowski, M.; Offenberg, J. H.; Jaoui, M.; Edney, E. O. Ozoneisoprene reaction: Re-examination of the formation of secondary organic aerosol. Geophys. Res. Lett. 2007, 34, L01805.

46. Liu, Q.; Abbatt, J. P. Liquid crystal display screens as a source for indoor volatile organic compounds. Proc. Natl. Acad. Sci. U. S. A. 2021, 118 (23), e2105067118.

47. Nicolaides, N. Skin lipids: Their biochemical uniqueness. Science 1974, 186, 19-26.

48. Ehn, M.; J. A. Thornton; E. Kleist; M. Sipilä; H. Junninen; I. Pullinen; M. Springer; F. Rubach; R. Tillmann; B. Lee; F. Lopez-Hilfiker; S. Andres; I.-H. Acir; M. Rissanen; T. Jokinen; S. Schobesberger; J. Kangasluoma; J. Kontkanen; T. Nieminen; T. Kurtén; L. B. Nielsen; S. Jørgensen; H. G. Kjaergaard; M. Canagaratna; M. D. Maso; T. Berndt; T. Petäjä; A. Wahner; V.-M. Kerminen; M. Kulmala; D. R. Worsnop; J. Wildt; T. F. Mentel. A large source of lowvolatility secondary organic aerosol. Nature 2014, 506, 476-479.

49. Kroll, J. H.; Seinfeld, J. H. Chemistry of secondary organic aerosol: Formation and evolution of low-volatility organics in the atmosphere. Atmos. Environ. 2008, 42, 3593-3624.

50. Avery, A. M.; Waring, M. S.; DeCarlo, P. F. Human occupant contribution to secondary aerosol mass in the indoor environment. Environ. Sci.: Process. Impacts 2019, 21, $1301-1312$.

51. K. Lai, A. C.; Nazaroff, W. W. Modeling indoor particle deposition from turbulent flow onto smooth surfaces. J. Aerosol Sci. 2019, 31 (4), 463-476.

52. Docherty, K. S.; Wu, W.; bin Lim, Y.; Ziemann, P. J. Contributions of organic peroxides to secondary aerosol formed from reactions of monoterpenes with O3. Environ. Sci. Technol. 2005, 39, 4049-4059. 
53. Nah, T.; Kessler, S. H. ; Daumit, K. E.; Kroll, J. H.; Leone, S. R.; Wilson, K. R. Influence of molecular structure and chemical functionality on the heterogeneous $\mathrm{OH}$-initiated oxidation of unsaturated organic particles. J. Phys. Chem. A. 2014, 118, 4106-4119.

54. Henze, D. K.; Seinfeld, J. H. Global secondary organic aerosol from isoprene oxidation. Geophys. Res. Lett. 2006, 33, L09812.

55. Na, K.; Song, C.; Switzer, C.; Cocker, D. R. Effect of ammonia on secondary organic aerosol formation from $\alpha$-pinene ozonolysis in dry and humid conditions. Environ. Sci. Technol. 2007, 41, 6096-6102.

56. Hao, L.; Kari, E.; Leskinen, A.; Worsnop, D. R.; Virtanen, A. Direct contribution of ammonia to $\alpha$-pinene secondary organic aerosol formation. Atmos. Chem. Phys. 2020, 20, $14393-14405$.

57. Nazaroff, W W.; Weschler, C. J. Indoor acids and bases. Indoor Air 2020, 30, 559-644. 58. Ortega, I. K.; Kupiainen, O.; Kurtén, T.; Olenius, T.; Wilkman, O.; McGrath, M. J.; Loukonen, V.; Vehkamäki, H. From quantum chemical formation free energies to evaporation rates. Atmos. Chem. Phys. 2012, 12, 225-235.

59. Chen, H.; Varner, M. E.; Gerber, R. B.; Finlayson-Pitts, B. J. Reactions of methanesulfonic acid with amines and ammonia as a source of new particles in air. J. Phys. Chem. B. 2016, 120, 1526-1536.

60. Elm, J. Toward a holistic understanding of the formation and growth of atmospheric molecular clusters: A quantum machine learning perspective. J. Phys. Chem. A. 2021, 125, 895902.

61. Praske, E.; Otkjær, R. v.; Crounse, J. D.; Hethcox, J. C.; Stoltz, B. M.; Kjaergaard, H. G.; Wennberg, P. O. Atmospheric autoxidation is increasingly important in urban and suburban North America. Proc. Natl. Acad. Sci. U. S. A. 2018, 115, 64-69. 
62. Pagonis, D.; Algrim, L. B.; Price, D. J.; Day, D. A.; Handschy, A. v.; Stark, H.; Miller, S. L.; de Gouw, J. A.; Jimenez, J. L.; Ziemann, P. J. Autoxidation of limonene emitted in a university art museum. Environ. Sci. Technol. Lett. 2019, 9, 520-524.

63. Zeng, M.; Heine, N.; Wilson, K. R. Evidence that Criegee intermediates drive autoxidation in unsaturated lipids. Proc. Natl. Acad. Sci. U. S. A. 2020, 117, 4486-4490.

64. Chan, T.; Cai, R.; Ahonen, L. R.; Liu, Y.; Zhou, Y.; Vanhanen, J.; Dada, L.; Chao, Y.; Liu, Y.; Wang, L.; Kulmala, M.; Kangasluoma, J. Assessment of Particle Size Magnifier inversion methods to obtain the particle size distribution from atmospheric measurements. Atmos. Meas. Tech. 2020, 13 (9), 4885-4898.

65. Wang, N.; Zannoni, N.; Ernle, L.; Bekö, G.; Wargocki, P.; Li, M.; Weschler, C. J.; Williams, J. Total $\mathrm{OH}$ reactivity of emissions from humans: in-situ measurement and budget analysis. Environ. Sci. Technol. 2021, 55, 149-159.

66. Weschler, C. J.; Langer, S.; Fischer, A.; Bekö, G.; Toftum, J.; Clausen, G. Squalene and cholesterol in dust from Danish homes and daycare centers. Environ. Sci. Technol. 2011, $45,3872-3879$.

67. Liu, Y.; Misztal, P. K. ; Arata, C.; Weschler, C. J.; Nazaroff, W. W.; Goldstein, A. H. Observing ozone chemistry in an occupied residence. Proc. Natl. Acad. Sci. U. S. A. 2021, 118, e2018140118.

68. Salonen, H.; Salthammer, T.; Morawska, L. Human exposure to ozone in school and office indoor environments. Environ. Int. 2018, 119, 503-514.

69. Yang, S.; Nie, J.; Wei, F.; Yang, X. Carbon nanotubes/activated carbon fiber based air filter media for simultaneous removal of particulate matter and ozone. Build. Environ. 2017, $125,60-66$. 
749 70. Yang, S.; Zhu, Z.; Wei, F.; Yang, X. Removal of ozone by carbon nanotubes/quartz $750 \quad$ fiber film. Environ. Sci. Technol. 2016, 50 (17), 9592-9598.

751 71. Weschler, C. J. Ozone in indoor environments: concentration and chemistry. Indoor Air $752 \quad 2000,10(4), 269-288$. 